\title{
Structural Equation Modelling in the exploration and analysis of intrauterine environmental exposures with infant health effects
}

\author{
Macarena Valdés Salgado ${ }^{1, A-F \oplus}$, Magdalena Bastías ${ }^{1, C-F \oplus}$, Enrique Schisterman ${ }^{2, A, C, E-F \oplus}$, \\ Paulina Pino ${ }^{1, A, C-F \oplus}$, Shrikant Bangdiwala ${ }^{3, A, C, E-F \oplus}$, Verónica Iglesias ${ }^{1, A, C-F \oplus}$ \\ ${ }^{1}$ Faculty of Medicine, School of Public Health, University of Chile, Santiago, Chile \\ ${ }^{2}$ Epidemiology Branch Chief, Eunice Kennedy Shriver National Institute of Child Health and Human Development, \\ Maryland, USA \\ ${ }^{3}$ Faculty of Health Science, Population Health Research Institute, McMaster University, Hamilton, Canada \\ A - Research concept and design, B - Collection and/or assembly of data, C - Data analysis and interpretation, \\ $D$ - Writing the article, E - Critical revision of the article, F - Final approval of article
} Valdés Salgado M, Bastías M, Schisterman E, Pino P, Bangdiwala S, Iglesias V. Structural Equation Modelling in the exploration and analysis
of intrauterine environmental exposures with infant health effects. Ann Agric Environ Med. 2019; 26(4): 617-622. doi: 10.26444/aaem/114724

\begin{abstract}
Introduction. In epidemiology, generalized linear models are the main statistical methods used to explore associations. However, the use of other methods such as Structural Equation Modelling (SEM) is gradually increasing.

Objective. The aim of the study was to illustrate the use of SEM in the assessment of salivary cortisol concentration in infants as a biomarker of perinatal exposure to inorganic arsenic.

Materials and method. This was a cohort study of pregnant women recruited from public health care centres in Arica, Chile, in 2013. Socio-demographic information and urine samples to assess inorganic arsenic were collected during the second trimester of pregnancy. Saliva samples were collected to assess cortisol in infants between 18-24 months of age. Four linear regression models (LRMs) and two SEMs were run to estimate the effect of prenatal exposure to inorganic arsenic on cortisol concentration in infants.

Results. According to LRMs and SEMs, prenatal exposure to inorganic arsenic and salivary cortisol were not associated. However, the association between maternal cortisol and cortisol in infants was statistically significant in all models; for each increase in standard deviation of the covariate $\mathrm{Ln}$ (maternal cortisol), the outcome Ln(cortisol in infant) increased by 0.49 units of variance in both SEMs.

Conclusions. LRMs and SEMs were useful to assess the effect of prenatal exposure to inorganic arsenic on cortisol in infants. However, SEM allowed the adjustment of estimations by an estimated latent that obtained the information about income, occupation, education and ethnicity in a more comprehensive way than achieved by LRM.
\end{abstract}

\section{Key words}

structural equation model, cohort study, arsenic, Chile, intrauterine exposure

\section{INTRODUCTION}

Researchers have multiple tools at their disposal to explore and analyse the data obtained. In the field of epidemiology, generalized linear models are the main statistical methods used in the assessment of associational and causal relations. However, the use of other methods, such as Structural Equation Modelling (SEM), is gradually increasing. SEM is a set of statistical procedures used to simultaneously evaluate several associational pathways among variables. It has been applied mainly in social sciences with labels such as covariance structure analysis, analysis of covariance, factorial analysis, principal component analysis, or pathways analysis. As in linear regression, there are assumptions in SEM whose verification is a critical stage to obtain valid estimates [1].

Address for correspondence: Macarena Alejandra Valdés Salgado, School of Public Health. Faculty of Medicine. University of Chile, 939 Av. Independencia, 8380453, Santiago, Chile

E-mail: macavaldes@ug.uchile.cl

Received: 09.09.2019; Accepted: 25.11.2019; first published: 10.12.2019
SEM is especially useful in the estimation of latent variables where measurement is either difficult or not yet possible (e.g. socio-economic status) [2-4]; thus, latent variables are approximated by researchers from proxy variables (e.g. income, occupation, education). In linear regression models, proxies should be assessed one at a time (i.e. one proxy per latent variable per model) as a way to reduce multi-collinearity. By contrast, SEM encompass all proxies simultaneously and provide the researcher with one coefficient that captures the complexity of their interrelationship [5].

The use of SEM in data exploration and analysis may contribute to increasing the researcher's understanding of how the selected proxies interrelate to constitute a latent exposure, and how these all relate to other variables in the model simultaneously.

Linear Regression Analysis. The method of linear regression is used to estimate the best-fitting straight line to describe the relation between a numerical outcome and an exposure. It provides an estimate of the correlation coefficient, which is a measure of the strength of the association. Linear 
regression analysis gives the equation of the straight line that best describes how the outcome increases or decreases as a function of the exposure variable. The equation for the regression line is

$$
Y=\beta_{0}+\beta_{1} X \mathrm{i}+\varepsilon
$$

where $\beta_{0}$ and $\beta_{1}$ are the parameters or regression coefficients of the linear regression: $\beta_{0}$ is the intercept (i.e. value of $y$ when $x=0$ ), and $\beta_{1}$ the slope of the line.

\section{Assumptions}

- Linearity of the relation between the independent variable $X i$ and the dependent variable $Y$.

- For any value of the independent variable $X_{i}$, the dependent variable $Y$ is normally distributed (residuals are independently, identically distributed-i.i.d-).

- The magnitude of the scatter of the points around the line is the same throughout the length of the line (Homoscedasticity).

- There should be no correlation between independent variables; this phenomenon, known as collinearity, reduces the efficiency of the model.

Structural Equation Modelling. A structural equation model is a conceptual representation of a phenomenon that is a product of the interrelation among random variables and structural parameters [6]. A graphic representation of the conceptual model is known as a pathway diagram and it is an approximation of the statistical model (Fig. 1).

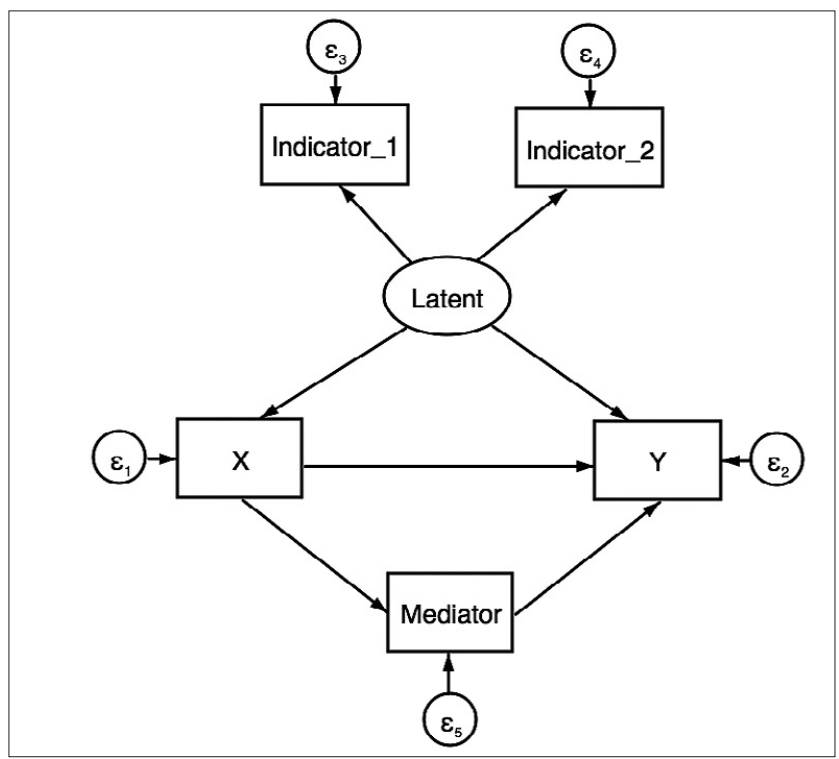

Figure 1. Generic pathway diagram. $X$ is the independent variable and has a direct effect on the dependent variable $Y$ and an indirect effect through the mediator. The direct effect is confounded by a latent variable, which has two proxies or indicators.

Random variables. In a pathway diagram, there are usually four types of random variables: observed, indicator and latent variables, and errors. In the diagrams, observed variables are represented by rectangles, latent with ovals, and errors with $\varepsilon \sigma$. An indicator is a type of observed variable that is used in the latent variable estimation. Additionally, an effect variable (indicated by one or more arrows) is known as an endogenous variable, while those not indicated by an arrow are named exogenous.
Structural parameter. Structural parameters are the variances, regression coefficients and c-variances among variable, defined between cause and effect variables. Arrows that link them imply causal hypothesis. Estimation of the structural equation system quantifies the structural parameter for each equation and the measurement parameters for indicators. Measurement parameters quantify the relation between an indicator and a latent variable. To estimate measurement parameters, it is necessary to constrain one of the indicators; as a result, the number of measurement parameters for $\mathrm{k}$ indicators is ( $\mathrm{k}-1)$ [5].

\section{Assumptions}

- Linearity: In order to satisfy this assumption within the multiple linear regression models fit by SEM, transformation of variables is justified (e.g. logarithm or square root transformation).

- Identifiability: A model is identifiable when it is theoretically possible to estimate the true values of the model's underlying parameters when the sample size tends to the infinite. The first step for identifiability verification is the counting rule: the number of free parameters must not exceed the number of variances and co-variance between the observable variables (1), shown by:

$$
\frac{(p+q) *(p+q+1)}{2}
$$

- Other tools for identifiability verification: (i) corroboration that measurement errors are not correlated; (ii) at least two exclusive indicators exist for each latent variable; or when there is only one single indicator, its measurement error is zero; and (iii) the model contains only observable variables.

- Goodness of fit: can be assessed using different criteria. The most frequently used are: root mean square error of approximation (RMSEA) with a value $<0.05$; comparative fit index (CFI) with a value $>0.95$; Tucker-Lewis index (TLI) with a value $>0.95$ or Coefficient of Determination (CD) which must be close to 1 . These may be used together as an overall fit measurement.

- Maximization of the goodness of fit: may be achieved by model modification. Modification indexes are diagnostic tools available in statistical packages that can identify new combinations of covariance matrices that could contribute to reduce the $\chi^{2}$ statistic of the over-all goodness of fit. Also, Akaike and Bayesian information criteria may be used for comparisons between SEMs.

- Pathway diagram: this should reflect the robustness of a SEM; a robust theoretical model underlying SEM should lead to similar estimations after small modifications to the model.

\section{OBJECTIVE}

By setting linear regression analysis as a reference statistical tool, the aim was to illustrate the use of SEM in the study of salivary cortisol concentration in infants as a biomarker of arsenic exposure during pregnancy. 


\section{METHOD}

Sample and variables. The data was obtained from a cohort study o' "Prenatal exposure to low-level inorganic arsenic concentrations associated with salivary cortisol in infants from Arica, Chile [7]. All pregnant women attending public health centres in Arica who were in the second trimester of pregnancy were invited to participate voluntarily between June - October 2013; an informed consent form was obtained. A questionnaire to record socio-demographic data was applied, and urine samples collected to assess inorganic arsenic species.

During the first year after childbirth, a standardized questionnaire was applied by a medical doctor to register information pertaining to depression diagnosed, and selfreport of stressful pregnancy. At months 18 - 24 after birth, saliva samples were collected from mothers and children during home visits to assess cortisol. A detailed description of the study is available elsewhere [7].

Inorganic arsenic was measured using high-performance liquid chromatography and inductively coupled plasma mass spectrometry (HPLC-ICPMS) in the Laboratory Trace Metals Core of the University of Columbia, New York, USA, as the sum of arsenate (AsV), arsenite (AsIII), monomethyl arsenic (MMA), and dimethyl arsenic (DMA); this variable was measured in a continuous scale $(\mu \mathrm{g} / \mathrm{L})$. Quantitative determination of salivary cortisol was performed with enzymelinked immunosorbent assay (ELISA) at the Biotechnology Laboratory of Bernardo O'Higgins University, Santiago, Chile; it was also measured in a continuous scale $(\mu \mathrm{g} / \mathrm{dL})$.

Depression diagnosed by a medical doctor was registered in a dichotomist scale (yes/no); self-report of stressful pregnancy (very low and low /moderate/high or very high), and monthly family income (<307 USD, 307 - 613 USD, $614-$ 920 USD, 921 - 1,229 USD, >1,229 USD) were registered in an ordinal scale. Mother's educational level (years of education) in a discrete scale; ethnicity (mixed-race, Aymara/other indigenous ethnicities) and occupation (student, housewife or remunerated job) in a nominal scale.

Statistical analyses - Linear Regression. To satisfy linear regression analysis assumptions, numerical variables were logtransformed. Maternal postpartum depression and stressful pregnancy were treated as a binary variable; income and education were ordinal variables, the maternal occupation that was transformed into dummies and ethnicity was considered as a binary variable. To avoid multi-collinearity, four regression models were explored according to each individual SES proxy, i.e. income, education, occupation, and ethnicity. Models were compared with adjusted $\mathrm{R}^{2}$ and goodness of fit checked with analysis of residuals. Analyses were conducted using Stata version IC v14.0.

SEM. Exposure to inorganic arsenic has been associated with several pregnancy and perinatal outcomes [8-10]. Toxicological studies have indicated that low-level exposure during pregnancy could be related to increased levels of cortisol [11-13]. In humans, cortisol level has been related to factors such as socio-economic status (SES), working conditions and stressful situations [14-16].

Figures 2 and 3 are pathway diagrams representing these complex relations. In both diagrams, SES indicator variables (income, education, occupation, and ethnicity) were defined according to the social determinants of health framework [17]. SEM 1 (Fig. 2) shows the direct effect model of exposure to inorganic arsenic while SEM 2 (Fig. 3) included the indirect effect of exposure to inorganic arsenic through maternal depression as mediator.

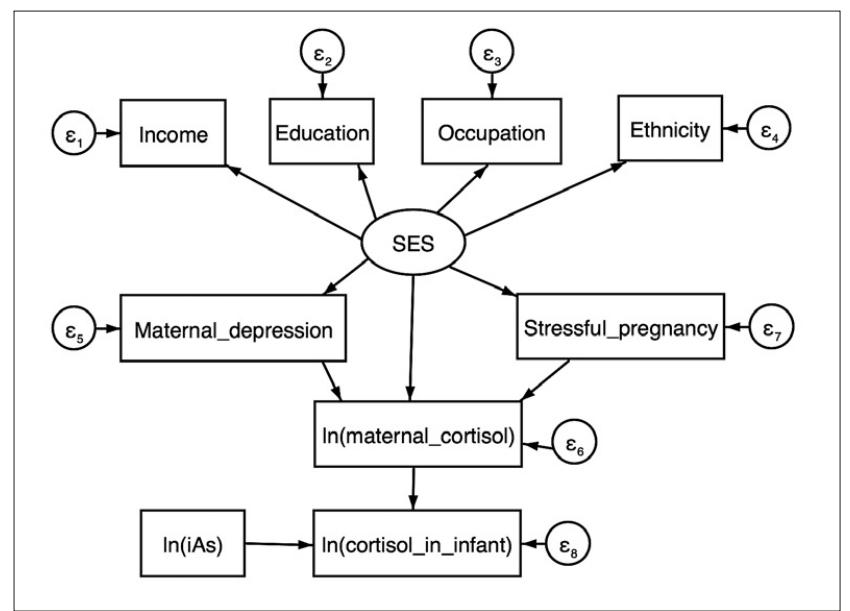

Figure 2. Pathway diagram. $\operatorname{Ln}(\mathrm{iAs})$ is the exposure variable and its effect on Ln(cortisol in infants) is estimated by a potential structural parameter. SES is a latent covariate

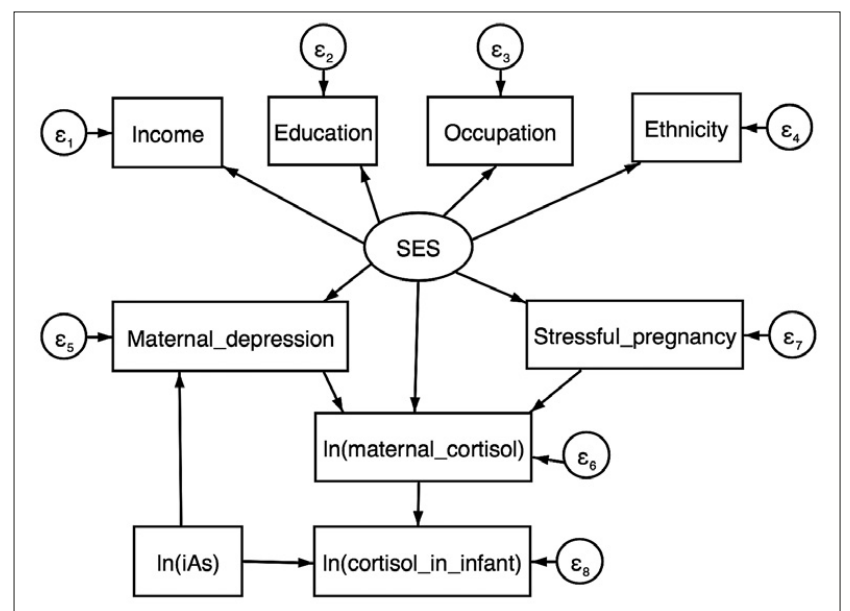

Figure 3. Pathway diagram adding an indirect effect of $L n(i A s)$ on $L$ (cortisol in infants) through the maternal depression - mediator variable

To satisfy SEM assumptions, numerical variables were logtransformed. Maternal postpartum depression was treated as a binary variable; income and education were ordinal variables, the maternal occupation that was transformed into dummies and ethnicity was considered as a binary variable.

Prenatal exposure to inorganic arsenic was an exogenous and observed random variable, and salivary cortisol was an endogenous and observed random variable. All endogenous variables included random error, and it was assumed that exogenous variables were measured without random error. Prenatal exposure to inorganic arsenic, maternal postpartum depression, stressful pregnancy and maternal cortisol were modelled as having a direct effect on cortisol in infants (Tab. 1).

To verify the identifiability in both SEMs, 13 free parameters (9 structural and 4 measurement parameters) were estimated in SEM 1, and 14 free parameters (10 structural and 4 measurement parameters) in SEM 2. Consequently, a third structural equation model was specified to test the robustness of the estimations. 
Table 1. Structural equations in the pathway diagram

\begin{tabular}{clcc}
\hline Equation & Independent variables & $\begin{array}{c}\text { Dependent } \\
\text { variable }\end{array}$ & $\begin{array}{c}\text { No. of } \\
\text { parameters }\end{array}$ \\
\hline 1 & $\begin{array}{l}\text { Ln(iAs); maternal depression; stressful } \\
\text { pregnancy; Ln(maternal cortisol) }\end{array}$ & $\begin{array}{c}\text { Ln(cortisol } \\
\text { in infants) }\end{array}$ & $\begin{array}{c}4 \text { structural } \\
\text { parameters }\end{array}$ \\
\hline 2 & $\begin{array}{l}\text { SES; maternal depression; stressful } \\
\text { pregnancy }\end{array}$ & $\begin{array}{c}\text { Ln(maternal } \\
\text { cortisol) }\end{array}$ & $\begin{array}{c}3 \text { structural } \\
\text { parameters }\end{array}$ \\
\hline 3 & SES & $\begin{array}{c}\text { maternal } \\
\text { depression }\end{array}$ & $\begin{array}{c}1 \text { structural } \\
\text { parameter }\end{array}$ \\
\hline 4 & SES & $\begin{array}{c}\text { stressful } \\
\text { pregnancy }\end{array}$ & $\begin{array}{c}1 \text { structural } \\
\text { parameter }\end{array}$ \\
\hline 5 & $\begin{array}{l}\text { Income; education; occupation } \\
\text { ethnicity }\end{array}$ & SES & $\begin{array}{c}3 \text { measurement } \\
\text { parameters }\end{array}$ \\
\hline
\end{tabular}

a Indicator variables

Model fit was evaluated using the root mean square error of approximation (RMSEA) with a value $<0.05$, the comparative fit index (CFI) with a value $>0.95$, a Tucker-Lewis index (TLI) with a value $>0.95$ and the Coefficient of determination (CD) which must be close to 1 . Akaike and Bayesian information criteria were used to compare models. Potential modification of the model was assessed. Analyses were conducted using Stata version IC v14.0.

\section{RESULTS}

General description. Characteristics of the sample are shown in Table 2. Quantitative variables as inorganic arsenic,

Table 2. Statistical summaries of observed variables

\begin{tabular}{|c|c|c|}
\hline Variable & $\mathrm{n}(\%)$ & Median $\left(\mathrm{P}_{25^{\prime}} ; \mathrm{P}_{75}\right)$ \\
\hline \multicolumn{2}{|c|}{$\begin{array}{l}\text { Prenatal inorganic arsenic concentration in mother's urine } \\
(\mu \mathrm{g} / \mathrm{L})\end{array}$} & $14.1(10.4 ; 14.1)$ \\
\hline \multicolumn{2}{|c|}{ Salivary cortisol concentration in child ( $\mu \mathrm{g} / \mathrm{dL})$} & $0.17(0.11 ; 0.17)$ \\
\hline \multicolumn{2}{|c|}{ Salivary cortisol concentration in mother $(\mu \mathrm{g} / \mathrm{dL})$} & $0.23(0.15 ; 0.23)$ \\
\hline \multicolumn{3}{|l|}{ Maternal Ethnicity } \\
\hline Mixed-race & \multicolumn{2}{|l|}{$113(67.7)$} \\
\hline Aymara/Other & \multicolumn{2}{|l|}{$47(28.1)$} \\
\hline \multicolumn{2}{|l|}{ Maternal education in years } & $12(12 ; 12)$ \\
\hline \multicolumn{3}{|l|}{ Family Income } \\
\hline$<307$ USD & \multicolumn{2}{|l|}{$63(38.2)$} \\
\hline $307-613$ USD & \multicolumn{2}{|l|}{$70(42.4)$} \\
\hline $614-920$ USD & \multicolumn{2}{|l|}{$16(9.7)$} \\
\hline $921-1,229$ USD & \multicolumn{2}{|l|}{$19(6.1)$} \\
\hline$>1,229$ USD & \multicolumn{2}{|l|}{$6(3.6)$} \\
\hline \multicolumn{3}{|l|}{ Maternal Occupation } \\
\hline Student & \multicolumn{2}{|l|}{$40(25.0)$} \\
\hline Housewife & \multicolumn{2}{|l|}{$76(47.5)$} \\
\hline Remunerated employment & \multicolumn{2}{|l|}{$44(27.5)$} \\
\hline \multicolumn{3}{|l|}{ Stressful pregnancy } \\
\hline Very low or low & \multicolumn{2}{|l|}{$54(33.1)$} \\
\hline Moderate & \multicolumn{2}{|l|}{$84(51.5)$} \\
\hline High or very high & \multicolumn{2}{|l|}{$25(15.4)$} \\
\hline \multicolumn{3}{|c|}{ Maternal depression diagnosed by a medical doctor } \\
\hline Yes & \multicolumn{2}{|l|}{$37(22.7)$} \\
\hline No & \multicolumn{2}{|l|}{$126(77.3)$} \\
\hline
\end{tabular}

maternal cortisol, and cortisol in infants were positively skewed.

Linear Regression Models. Treating each SES proxy separately, 4 linear regression models were run to study the association between exposure to arsenic and cortisol in infants (Tab. 3). All models estimated similar regression coefficients for $\operatorname{Ln}(\mathrm{iAs})$, and the association between cortisol in infants and mothers was statistically significant ( $\mathrm{p}$-value: $<0.001$ ) in all 4 . Adjusted $\mathrm{R}^{2}$ varied from $0.2011-0.211$, and the residual analysis showed symmetrical distribution of residuals with mean equal to zero.

Table 3. Linear regression model coefficients for income, education, occupation and ethnicity as proxies of SES treated separately.

\begin{tabular}{|c|c|c|c|c|c|}
\hline Model & Variables & Coefficient & $95 \% \mathrm{Cl}$ & P-value & Adjusted $R^{2}$ \\
\hline \multirow[t]{5}{*}{1} & $\operatorname{Ln}(\mathrm{iAs}) \mu \mathrm{g} / \mathrm{L}$ & 0.099 & $-0.128 ; 0.325$ & 0.391 & 0.2018 \\
\hline & $\begin{array}{l}\text { Ln(Maternal } \\
\text { cortisol) } \mu \mathrm{g} / \mathrm{L}\end{array}$ & 0.522 & $0.367 ; 0.676$ & $<0.001$ & \\
\hline & $\begin{array}{l}\text { Moderate or high } \\
\text { stress during } \\
\text { pregnancy }\end{array}$ & -0.089 & $-0.465 ; 0.288$ & 0.643 & \\
\hline & Maternal depression & 0.057 & $-0.264 ; 0.378$ & 0.726 & \\
\hline & $\begin{array}{l}\text { Monthy family } \\
\text { income }\end{array}$ & -0.008 & $-0.138 ; 0.121$ & 0.899 & \\
\hline \multirow[t]{5}{*}{2} & $\operatorname{Ln}(\mathrm{iAs}) \mu \mathrm{g} / \mathrm{L}$ & 0.107 & $-0.112 ; 0.326$ & 0.336 & 0.2064 \\
\hline & $\begin{array}{l}\mathrm{L}(\text { Maternal cortisol) } \\
\mu \mathrm{g} / \mathrm{L}\end{array}$ & 0.523 & $0.370 ; 0.675$ & $<0.001$ & \\
\hline & $\begin{array}{l}\text { Moderate/high stress } \\
\text { during pregnancy }\end{array}$ & -0.090 & $-0.458 ; 0.279$ & 0.631 & \\
\hline & Maternal depression & 0.063 & $-0.253 ; 0.379$ & 0.695 & \\
\hline & Years of education & 0.001 & $-0.042 ; 0.044$ & 0.949 & \\
\hline \multirow[t]{7}{*}{3} & $\operatorname{Ln}(\mathrm{iAs}) \mu \mathrm{g} / \mathrm{L}$ & 0.100 & $-0.126 ; 0.327$ & 0.382 & 0.2011 \\
\hline & $\begin{array}{l}\text { Ln(Maternal } \\
\text { cortisol) } \mu \mathrm{g} / \mathrm{L}\end{array}$ & 0.519 & $0.364 ; 0.674$ & $<0.001$ & \\
\hline & $\begin{array}{l}\text { Moderate/high stress } \\
\text { during pregnancy }\end{array}$ & -0.086 & $-0.462 ; 0.290$ & 0.652 & \\
\hline & Maternal depression & 0.075 & $-0.250 ; 0.401$ & 0.648 & \\
\hline & Occupation: worker & Reference & & & \\
\hline & Occupation: student & 0.172 & $-0.199 ; 0.542$ & 0.522 & \\
\hline & $\begin{array}{l}\text { Occupation: } \\
\text { housewife }\end{array}$ & 0.103 & $-0.215 ; 0.421$ & 0.002 & \\
\hline \multirow[t]{6}{*}{4} & $\operatorname{Ln}(\mathrm{iAs}) \mu \mathrm{g} / \mathrm{L}$ & 0.119 & $-0.101 ; 0.339$ & 0.286 & 0.2111 \\
\hline & $\begin{array}{l}\text { Ln(Maternal } \\
\text { cortisol) } \mu \mathrm{g} / \mathrm{L}\end{array}$ & 0.524 & $0.372 ; 0.676$ & $<0.001$ & \\
\hline & $\begin{array}{l}\text { Moderate/high stress } \\
\text { during pregnancy }\end{array}$ & -0.076 & $-0.445 ; 0.294$ & 0.686 & \\
\hline & Maternal depression & 0.061 & $-0.254 ; 0.375$ & 0.704 & \\
\hline & Ethnicity: mixed race & Reference & & & \\
\hline & $\begin{array}{l}\text { Aymara/other_ } \\
\text { ethnicity }\end{array}$ & -0.123 & $-0.404 ; 0.157$ & 0.386 & \\
\hline
\end{tabular}

Structural Equation Modelling. SEM 1- direct effect model of arsenic exposure- showed no association between arsenic exposure and cortisol, and a statistically significant positive effect of maternal cortisol on cortisol in infants (Table 4). SEM 2-indirect effect of arsenic exposure through maternal depression as mediator- showed no effect of arsenic exposure on cortisol in infants either direct or indirect, and a statistically significant positive effect of maternal cortisol on cortisol in infants (Table 4). 
Table 4. Structural equation parameter for $\operatorname{Ln}(\mathrm{iAs})$ and covariables

\begin{tabular}{|c|c|c|c|c|c|c|c|}
\hline \multirow[t]{2}{*}{ SEM } & \multirow[t]{2}{*}{ Variables } & \multicolumn{2}{|c|}{ Direct Effect } & \multicolumn{2}{|c|}{ Indirect Effect } & \multicolumn{2}{|c|}{ Total Effect } \\
\hline & & Coef. & $95 \% \mathrm{Cl}$ & Coef. & $95 \% \mathrm{Cl}$ & Coef. & $95 \% \mathrm{Cl}$ \\
\hline \multirow[t]{4}{*}{1} & $\operatorname{Ln}(\mathrm{iAs}) \mu \mathrm{g} / \mathrm{L}$ & 0.085 & $-0.124 ; 0.294$ & NPa & & 0.085 & $-0.124 ; 0.294$ \\
\hline & $\operatorname{Ln}($ Maternal cortisol) $\mu \mathrm{g} / \mathrm{dL}$ & 0.545 & $0.399 ; 0.691$ & NPa & & 0.545 & $0.399 ; 0.691$ \\
\hline & Moderate/high stress during pregnancy & -0.088 & $-0.443 ; 0.267$ & 0.13 & $-0.072 ; 0.333$ & 0.043 & $-0.367 ; 0.452$ \\
\hline & Maternal depression & 0.064 & $-0.240 ; 0.368$ & 0.092 & $-0.087 ; 0.271$ & 0.156 & $-0.199 ; 0.511$ \\
\hline \multirow[t]{5}{*}{2} & $\operatorname{Ln}(\mathrm{iAs}) \mu \mathrm{g} / \mathrm{L}$ & 0.085 & $-0.124 ; 0.294$ & 0.003 & $-0.015 ; 0.021$ & 0.088 & $-0.121 ; 0.297$ \\
\hline & Ln(Maternal cortisol) $\mu \mathrm{g} / \mathrm{dL}$ & 0.545 & $0.399 ; 0.691$ & $\mathbf{N P a}$ & & 0.545 & $0.399 ; 0.691$ \\
\hline & Moderate/high stress during pregnancy & -0.088 & $-0.443 ; 0.267$ & 0.13 & $-0.072 ; 0.333$ & 0.042 & $-0.367 ; 0.452$ \\
\hline & Maternal depression & 0.063 & $-0.241 ; 0.367$ & 0.091 & $-0.087 ; 0.270$ & 0.154 & $-0.201 ; 0.510$ \\
\hline & SES & $N P^{a}$ & & 0.254 & $-0.464 ; 0.971$ & 0.254 & $-0.464 ; 0.971$ \\
\hline
\end{tabular}

aNP indicates no path

SEM 1 and SEM 2 identifiability were satisfactory (counting rule). Measurement errors were uncorrelated, there were no more than 2 exclusive indicators for the latent variable (SES); besides SES, the rest of the variables were observable.

SEM 1 and SEM 2 had satisfactory goodness of fit (Tab. 5). Akaike and Bayesian information criteria indicated better parsimony of SEM 2. According to modification indexes, the incorporation of an additional correlation between income and education would have improved goodness of fit in both models. The modification, however, would otherwise have implied loss of identifiability. Thus, SEM 1 and SEM 2 were kept as originally defined.

Table 5. Fit Indexes for both Structural Equation Models

\begin{tabular}{lccc}
\hline Index & $\begin{array}{c}\text { SEM1: Ln(iAs) } \\
\text { direct effect } \\
\text { model }\end{array}$ & $\begin{array}{c}\text { SEM 2: Ln(iAs) } \\
\text { direct and indirect } \\
\text { effects model }\end{array}$ & Good fit criteria \\
\hline $\begin{array}{l}X^{2} \text { P value } \\
\text { Root mean square } \\
\text { error of approximation } \\
\text { (RMSEA) }\end{array}$ & 0.326 & 0.286 & $>0.05$ \\
\hline $\begin{array}{l}\text { Akaike's information } \\
\text { criterion (AIC) }\end{array}$ & 3384.7 & 3386.6 & $\begin{array}{l}\text { Used to compare } \\
\text { between models }\end{array}$ \\
\hline $\begin{array}{l}\text { Bayesian information } \\
\text { criterion (BIC) }\end{array}$ & 3490.9 & 3495.9 & $\begin{array}{l}\text { Used to compare } \\
\text { between models }\end{array}$ \\
\hline \begin{tabular}{l} 
Comparative fit index \\
\hline Tucker-Lewis index
\end{tabular} & 0.973 & 0.965 & $>0.95$ \\
\hline $\begin{array}{l}\text { Coefficient of } \\
\text { determination }\end{array}$ & 0.961 & 0.948 & $>0.95$ \\
\hline
\end{tabular}

\section{DISCUSSION}

Linear regression analysis and SEM were useful for studying the effect of prenatal exposure to inorganic arsenic on salivary cortisol concentration in infants. SEM allowed the adjustment of estimations by a measure of SES that obtained the information about income, occupation, education and ethnicity in a more comprehensive way than LRM. Both methods required the same transformations of variables, which evens any difficulty in the interpretation of results.

The coefficient obtained under the linear regression approach for prenatal exposure to inorganic arsenic was similar to those obtained under SEM (SEM 1 and 2). However, in SEM 2, it was possible to explore the indirect effect of the prenatal exposure to inorganic arsenic on cortisol through a mediator (i.e. maternal depression); this was not feasible in LRM because it is not proper to adjust for mediators (i.e. over-adjustment bias and unnecessary adjustment) [18].

The linear regression coefficient estimation was similar for each SES proxy. Their value was similar to those estimated by SEM 1 and SEM 2; however, the information they contained was not comparable. SEMs estimated latent SES and further converged to estimate the effect of prenatal exposure to inorganic arsenic on infant's cortisol. SEM evaluated income, occupation, education, and ethnicity together, as occurs in real life: an individual has a certain income, has completed a specific level of education, has a particular occupation, and belongs to one ethnic group, all at the same time.

A strong association between child and maternal cortisol in both LRM and SEM was found; this seems plausible given the many factors, including habits or stressful experiences that affect both mother and child simultaneously [19]; the other relations in both SEMs did not reach statistical significance. For instance, a positive tendency was found between the latent variable SES with educational level [20, 21], showing that subjects who reported to be students had better SES than those with remunerated employment; those who reported having remunerated employment rated better than housewives. Nevertheless, none of these relationships were statistically significant.

In environmental epidemiology, recent studies have used SEMs to evaluate the impact of one pollutant on more than one health effect [22], or to estimate the effect of more than one pollutant acting concurrently in a spatial context [23]. In the field of arsenic research, authors such as Fei, Kyle and Davis [24-26] have applied SEM to study the association between prenatal exposure to inorganic arsenic and intercorrelated perinatal outcomes that may lie on the same pathway.

Limitations of the current study were the self-report quality of some variables, small sample size and the possible difficulties in interpretation of results due to necessary mathematical transformations. Self-reported could introduce bias while a larger sample size could improve estimation accuracy. Nevertheless, the aim of the study was achieved. 


\section{CONCLUSIONS}

The incorporation of SEM is recommend as one more step in the exploration and data analysis in epidemiology when applicable. In the past decades, studies in this field have become more complex as the epidemiological profile of populations has transitioned from single cause to multiple causes underlying disease. SEM may be of help in capturing such complexity and provide researchers with a more comprehensive estimation that could take them one step closer to the reality they aim to explain.

SEM was useful in assessing direct and indirect arsenic effects, considering latent ancestors as proxies for socioeconomic status, and a mediator of the mother's depression for the indirect effect; this gave a complementary approach to the traditional LRM approach.

Both analyses, LRMs and SEMs, were useful for investigating the effect of prenatal exposure to inorganic arsenic on cortisol in infants; however, SEM allowed adjusted estimations by an estimated latent SES that obtained the information about income, occupation, education and ethnicity in a more comprehensive way than LRM.

\section{REFERENCES}

1. VanderWeele TJ. Invited commentary: structural equation models and epidemiologic analysis. Am J Epidemiol. 2012; 176(7): 608-12.

2. Anderson JG. Structural Equation Models in the Social and Behavioral Sciences: Model Building. Child Development. 1987; 58(1): 49-64.

3. Violato C, Hecker KG. How to use structural equation modeling in medical education research: a brief guide. Teach Learn Med. 2007;19(4):362-71

4. Sánchez BN, Budtz-Jørgensen E, Ryan LM, Hu H. Structural Equation Models. Journal of the American Statistical Association. 2005; 100(472): 1443-55.

5. Kline RB. Principles and Practice of Structural Equaiton Modelling. Little TD, editor. United States of America: The Guilford Press; 2011.

6. Bollen K. Structural Equations with Latent Variables. United States of America: Willey; 1989.

7. Valdés M. Prenatal exposure to low-level inorganic arsenic concentrations associated with salivary cortisol in infants from Arica, Chile. Doctoral thesis Santiago, Chile: University of Chile; 2017.

8. Tsuji IS, Perez V, Garry MR, Alexander DD. Association of low-level arsenic exposure in drinking water with cardiovascular disease: a systematic review and risk assessment. Toxicology. 2014; 323: 78-94.

9. Tsuji JS, Garry MR, Perez V, Chang ET. Low-level arsenic exposure and developmental neurotoxicity in children: A systematic review and risk assessment. Toxicology. 2015; 337: 91-107.

10. Farzan SF, Chen Y, Rees JR, Zens MS, Karagas MR. Risk of death from cardiovascular disease associated with low-level arsenic exposure among long-term smokers in a US population-based study. Toxicol Applied Pharmacol. 2015; 287(2): 93-7.

11. Martinez-Finley EJ, Goggin SL, Labrecque MT, Allan AM. Reduced expression of MAPK/ERK genes in perinatal arsenic-exposed offspring induced by glucocorticoid receptor deficits. Neurotoxicol Teratol. 2011; 33(5): 530-7.

12. Martinez EJ, Kolb BL, Bell A, Savage DD, Allan AM. Moderate perinatal arsenic exposure alters neuroendocrine markers associated with depression and increases depressive-like behaviors in adult mouse offspring. Neurotoxicology. 2008; 29(4): 647-55.

13. Martinez-Finley EJ, Ali AM, Allan AM. Learning deficits in C57BL/6J mice following perinatal arsenic exposure: consequence of lower corticosterone receptor levels? Pharmacol Biochem Behav. 2009; 94(2): 271-7.

14. Badrick E, Bobak M, Britton A, Kirschbaum C, Marmot M, Kumari M. The relationship between alcohol consumption and cortisol secretion in an aging cohort. J Clin Endocrinol Metabol. 2008; 93(3): 750-7.

15. Eller NH, Netterstrom B Fau - Hansen AM, Hansen AM. Psychosocial factors at home and at work and levels of salivary cortisol. 2006; 03010511 (Print))

16. Kunz-Ebrecht SR, Kirschbaum C, Steptoe A. Work stress, socioeconomic status and neuroendocrine activation over the working day. Soc Sci Med. 2004; 58(8): 1523-30.

17. Solar O, Irwin A. A conceptual framework for action on the social determinants of health. Social Determinants of Health Discussion Paper 2 (Policy and Practice). WHO Library Cataloguin-in- Publication Data. 2010.

18. Schisterman EF, Cole SR, Platt RW. Overadjustment bias and unnecessary adjustment in epidemiologic studies. Epidemiol. 2009; 20(4): 488-95.

19. Khoury JE, Gonzalez A, Levitan R, Masellis M, Basile V, Atkinson L. Maternal self-reported depressive symptoms and maternal cortisol levels interact to predict infant cortisol levels. (1097-0355 (Electronic)).

20. Galobardes B, Shaw M, Lawlor DA, Lynch JW, Davey Smith G. Indicators of socioeconomic position (part 1). J Epidemiol Community Health. 2006; 60(1): 7-12.

21. Galobardes B, Shaw M, Lawlor DA, Lynch JW, Davey Smith G. Indicators of socioeconomic position (part 2). J Epidemiol Community Health. 2006; 60(2): 95-101.

22. Baja ES, Schwartz JD, Coull BA, Wellenius GA, Vokonas PS, Suh HH. Structural equation modeling of the inflammatory response to traffic air pollution. J Expo Sci Environ Epidemiol. 2013; 23(3): 268-74.

23. Fontanella L, Ippoliti L, Valentini P. Environmental pollution analysis by dynamic structural equation models. Environmetrics. 2007; 18(3): 265-83.

24. Fei DL, Koestler DC, Li Z, Giambelli C, Sanchez-Mejias A, Gosse JA, et al. Association between In Utero arsenic exposure, placental gene expression, and infant birth weight: a US birth cohort study. Environ Health. 2013; 12: 58.

25. Kile ML, Cardenas A, Rodrigues E, Mazumdar M, Dobson C, Golam $\mathrm{M}$, et al. Estimating Effects of Arsenic Exposure During Pregnancy on Perinatal Outcomes in a Bangladeshi Cohort. Epidemiology. 2016; 27(2): 173-81.

26. Davis MA, Li Z, Gilbert-Diamond D, Mackenzie TA, Cottingham KL, Jackson BP, et al. Infant toenails as a biomarker of in utero arsenic exposure. J Expo Sci Environ Epidemiol. 2014; 24(5): 467-73.

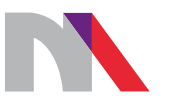

\section{Ministry of Science} and Higher Education

Republic of Poland

Generation of the DOI (Digital Object Identifier) - task financed under the agreement No. 618/P-DUN/2019 by the Minister of Science and Higher Education 